\title{
The buccale puzzle: The symbiotic nature of endogenous infections of the oral cavity
}

\author{
John Ruby DMD PhD¹, Jean Barbeau PhD²
}

J Ruby, J Barbeau. The buccale puzzle: The symbiotic nature of endogenous infections of the oral cavity. Can J Infect Dis 2002;13(1):34-41.

The indigenous, 'normal' microflora cause the majority of localized infectious diseases of the oral cavity (eg, dental caries, alveolar abscesses, periodontal diseases and candidiasis). The same microflora also protect the host from exogenous pathogens by stimulating a vigorous immune response and providing colonization resistance. How can a microflora that support health also cause endogenous oral disease? This paradoxical host-symbiont relationship will be discussed within the dynamic of symbiosis.

Symbiosis means 'life together' - it is capable of continuous change as determined by selective pressures of the oral milieu. Mutualistic symbiosis, where both the host and the indigenous microflora benefit from the association, may shift to a parasitic symbiosis, where the host is damaged and the indigenous microflora benefit. Importantly, these are reversible relationships. This microbial dynamism, called amphibiosis, is the essential adaptive process that determines the causation of endogenous oral disease by a parasitic microflora or the maintenance of oral health by a mutualistic microflora.
Complex microbial consortiums, existing as a biofilm, usually provide the interfaces that initiate and perpetuate the infectious assault on host tissue. The ecology of the various oral microhabitats is critical for the development of the appropriate selecting milieux for pathogens. The microbiota associated with dental caries progression are primarily influenced by the prevailing $\mathrm{pH}$, whereas periodontal diseases and pulpal infection appear to be more dependent on redox potential. Candidiasis results from host factors that favour yeast overgrowth or bacterial suppression caused by antibiotics. Oral health or disease is an adventitious event that results from microbial adaptation to prevailing conditions; prevention of endogenous oral disease can occur only when we realize that ecology is the heart of these host-symbiont relationships.

Key Words: Candidiasis; Dental caries; Normal flora; Oral infection; Periodontal diseases; Symbiosis

\footnotetext{
${ }^{1}$ Department of Pediatric Dentistry, School of Dentistry, The University of Alabama at Birmingham, Alabama; ${ }^{2}$ Faculty of Dentistry, University of Montreal, Quebec

Correspondence and reprints: Dr John Ruby, Department of Pediatric Dentistry, School of Dentistry, The University of Alabama at Birmingham, 304 School of Dentistry Building, 1919 Seventh Avenue South, Birmingham, AL 35294-0007, USA. Telephone 205-975-7003, fax 205-975-6773,e-mail john_ruby@cs1.dental.uab.edu

Received for publication November 22, 2001. Accepted December 10, 2001
} 


\section{Le casse-tête buccal : La nature symbiotique des infections endogènes de la cavité buccale}

RÉSUMÉ : La microflore indigène "normale" est responsable de la majorité des maladies infectieuses localisées de la cavité buccale (p. ex., caries dentaires, abcès alvéolaires, parodonthopathies et candidiases). La même microflore protège l'hôte des pathogènes exogènes en stimulant une réaction immunitaire intense et en offrant une résistance à la colonisation. Comment une microflore qui contribue à la santé peut-elle être responsable de maladies orales endogènes? Cette relation paradoxale entre l'hôte et le symbiote sera abordée selon la dynamique de la symbiose. Symbiose signifie "vivre ensemble"; elle est capable de modifications constantes déterminées par des contraintes sélectives du milieu buccal. Le mutualisme, où à la fois l'hôte et la microflore indigène profitent de l'association, peut se transformer en symbiose parasitaire, où l'hôte est endommagé tandis que la microflore indigène prospère. Il est important de souligner que ces relations sont réversibles. Ce dynamisme microbien, l'amphibiose, est le processus d'adaptation essentiel qui détermine l'apparition de maladies buccales endogènes par une microflore parasitaire, ou le maintien de la santé buccale par une microflore mutualiste. En général, des consortiums microbiens complexes, sous forme de film biologique, fournissent les interfaces qui introduisent et perpétuent l'agression infectieuse sur les tissus hôtes. L'écologie des divers microhabitats oraux est essentielle à l'apparition de milieux sélectifs adaptés aux pathogènes. La microbiote associée à la promotion de la carie dentaire est influencée principalement par le $\mathrm{pH}$ dominant, tandis que les parodonthopathies et les infections pulpaires semblent dépendre davantage du potentiel d'oxydoréduction. La candidiase résulte de facteurs propres à l'hôte, qui favorisent la prolifération mycosique ou la suppression bactérienne causée par les antibiotiques. La santé ou la maladie buccale est un événement accidentel suscité par l'adaptation microbienne aux conditions dominantes. La prévention d'une maladie buccale endogène n'est possible que si on comprend l'importance de l'écologie, au centre de ces relations entre l'hôte et le symbiote.

\section{"Everything is everywhere; but the milieu selects... in nature and in the laboratory."}

Bass Becking, 1934 (1)

W hy does our lifelong infection with the indigenous 'normal' microflora of the mouth cause disease? A complex microflora well adapted to a variety of microenvironments - a consortium of microorganisms comprised of more than 500 species, the majority of which remain unidentified (2). We begin to acquire a microflora soon after birth, are symbiotically associated with them for life, and they are passed on to the next generation for continuous co-evolution with the host $(3,4)$. A symbiotic microflora, when mutualistic with its host, stimulate a vigorous immune response and provides colonization resistance, both of which protect us from overt pathogens that may cause exogenous infectious disease (5). A microflora usually benign and essential for our well-being; yet, a protean microflora that may become parasitic and cause a variety of infectious oral diseases (eg, dental caries, pulpal infections, periodontal diseases and mucocutaneous candidiasis) (6). How can the same microflora that support health also cause endogenous disease? This is the buccale puzzle.

The key to unravelling this puzzle is to define the dynamic process that is intrinsic to relationships between the host and the microbial symbionts of the oral cavity. This dynamic is symbiosis or 'life together'. Once established, stable climax microbial communities are uniquely ours for a lifetime. They are associated intimately with the host and are in continuous flux because they adapt to the selective pressures of the oral milieu. Microbial adaptation in the human ecosystem is viewed as an amphibiotic response. An amphibiont is an organism with "a spectral position between probiosis and pathogenicity", as defined by Theodor Rosebury (7). Because endogenous oral disease is caused by heterogeneous microbial populations within biofilms, amphibiosis is viewed as a process of change that is caused by microbial consortiums as a whole. Amphibiosis is the essential process that determines the causation of endogenous infectious disease by a parasitic microflora or the maintenance of oral health by a mutualistic microflora, and is congruent with the 'ecological plaque hypothesis' that was proposed by Philip Marsh (8). This is the cognitive framework that facilitates our understanding of ecological relationships that involve complex communities of microorganisms as they interact with the host, resulting either in health or disease - the key to the buccale puzzle.

\section{SYMBIOSIS}

The etymology of symbiosis is from the Greek, meaning 'life together'. The term was introduced into biology in 1878 by Anton de Bary and was defined as "the living together of unlike organisms” (9). In 1876, Pierre-Joseph van Beneden, in his book Animal Parasites and Messmates, discussed the terms 'parasitism', 'commensalism' and 'mutualism' within the context of symbiosis. He wrote that the parasite "is he whose profession is to live at the expense of his neighbor, and whose only employment consists in taking advantage of him, but prudently, so as not to endanger his life," the commensal "is he who is received at the table of his neighbor to partake with him of the produce of his day's fishing...the messmate does not live at the expense of his host; all that he desires is a home or his friend's superfluities," and the "mutualists are animals which live on each other, without being either parasites or messmates...some render each other mutual services..." (9). Current definitions support these early biologists' ideas. Dorland's Illustrated Medical Dictionary, 29th edition (10), defines symbiosis as

...the living together or close association of two dissimilar organisms, each of the organisms being known as a symbiont. The association may be beneficial to both (mutualism), beneficial to one without effect on the other (commensalism), beneficial to one and detrimental to the other (parasitism)...

Stanier et al, in The Microbial World (11), embrace this definition and go on, importantly, to suggest that the character 
of the symbiosis is subject to change, depending on environmental conditions.

In mutalistic symbioses both partners benefit from the association; in parasitic symbioses one partner benefits, but the second gains nothing and often suffers more or less severe damage... the nature of a particular symbiosis can shift under changing environmental conditions, so that a relationship that starts out as mutualistic may become parasitic, or vice versa (11).

Symbiosis is a dynamic state that is capable of change, and this dynamism is called amphibiosis.

Symbiosis has also been defined more narrowly as mutualism, or a close association that brings benefit to both the host and the symbiont. In Jan Sapp's Evolution by Association (9), Sapp attributes symbiosis to be equated with mutualism, as in 19th century sociopolitical thought. In response to social Darwinism, symbiosis was given a beneficial denotation and evolved into mutualism (9). It is critical that the original concept of symbiosis (life together) be maintained. The language that is used in investigations of indigenous microbial populations that interact with host surfaces must be clear, and there must be a consensus of understanding among investigators. Defining symbiosis solely as mutualism is restrictive and limits our use of language; therefore, to understand this phenomenon, symbiosis must maintain its intended meaning - that of life together. Clear knowledge of this term is an essential first step to understanding the infinite possibilities that characterize the dynamic nature of host-symbiont interactions.

\section{DENTAL CARIES}

Dental caries is a localized, progressive decay of the teeth initiated by the demineralization of the outer surface of the tooth due to organic acids produced locally by bacteria that ferment deposits of dietary carbohydrates. With progressive loss of tooth mineral and secondary destruction of tooth protein by continued bacterial action, cavities form which, if untreated, extend and destroy most of the tooth, often leading to serious infection of the surrounding tissues... The development of caries requires critical relationships between tooth surface, oral microbiota and dietary carbohydrate (12).

The tooth is a unique anatomical tissue. Crown emamel and root cementum are nonshedding surfaces. Once teeth erupt into the oral cavity, they are immediately coated with salivary glycoproteins, which act as a substrate for subsequent colonization by microorganisms. The growth and coaggregation of microbes on the surfaces of teeth result in the development of an adherent biofilm, otherwise known as dental plaque (13). Plaque has a propensity to accumulate in retentive tooth areas that are free of shear forces generated by the oral musculature or dental mastication (eg, occlusal pits and fissures, approximal contacts, the gingival area surrounding the tooth and interfaces between fill- ings and surface enamel). Dental plaque is required for the formation of dental caries (14); however, dental caries is a conditional disease in that fermentable carbohydrates, primarily sucrose, are necessary for the formation of lactic acid (15). Lactic acid is the end product of glycolytic bacterial metabolism. When a $\mathrm{pH}$ of less than 5.5 is reached, surface demineralization usually occurs with eventual cavitation. The mutans streptococci (Streptococcus mutans and Streptococcus sobrinus) and lactobacilli are the primary etiologic agents of dental caries. Actinomyces species are also involved in root surface caries $(16,17)$. Oral cavities with healthy dentitions usually have decreased numbers of mutans streptococci in plaque deposits, low lactobacilli counts in saliva and high counts of Streptococcus sanguinis (18). Both reduced salivary flow and increased frequency of sugar consumption appear to be major contributors to the carious process. Reduced salivary flow results in increased fermentable carbohydrate retention, loss of fermentable substrate dilution and a diminished buffer capacity that is intrinsic to saliva, all of which lead to low $\mathrm{pH}$ conditions within the plaque. Sucrose is selective for the establishment of cariogenic microorganisms (19). The intermittent consumption of sucrose in people's diets sets up an enrichment culture within the oral cavity for the selection of chemoorganotrophic microorganisms that have evolved efficient metabolic pathways for energy production and storage during feast or famine conditions. Dental caries can, therefore, be viewed as a microbial adaptation to high energy fluxes that occur in the oral cavity. Lactic acid bacteria are microorganisms that have evolved physiological machinery to compete efficiently under these conditions (20).

The capacity of lactic acid bacteria to produce [acidogenic] and tolerate [aciduric] a relatively high concentration of lactic acid is of great selective value, since it enables them to eliminate competition from most other bacteria in environments that are rich in nutrients. This is shown by the fact that lactic acid bacteria can be readily enriched from natural sources through the use of complex media with a high sugar content. Such media can, of course, support the growth of many other chemoheterotrophic bacteria, but the competing organisms are largely eliminated as growth proceeds by the accumulation of lactic acid, formed through the metabolic activity of the lactic acid bacteria (11).

Mutans streptococci and lactobacilli are both acidogenic and aciduric. Their ability to thrive under low $\mathrm{pH}$ acid conditions in times of sucrose availability gives them a selective advantage over oral bacteria that are not acid tolerant (21). Although mutans streptococci and lactobacilli share the foregoing physiology that belongs to the lactic acid bacteria, they also have other characteristics that demonstrate further their highly specialized adaptation to environments where carbohydrate availability is in continuous flux. The synthesis of intracellular iodophilic polysaccharide (IPS) in times of carbohydrate excess, with later utilization of these 
storage compounds during energy deprivation, illustrates how these microorganisms have developed the enzymatic capability to survive under these special conditions of unbalanced growth. Extracellular reserve polymers, in the form of fructans, are degraded by mutans streptococci and may have a role similar to that of IPS (15). The affinity of mutans streptococci to colonize the dentition is enhanced in the presence of sucrose, and this appears to be due to the synthesis of extracellular glucans from sucrose by glucosyltransferases. Glucans function as a matrix for mutans streptococci accumulation in dental plaque. Moreover, glucans produce a biofilm with lower cell density, which results in the rapid uptake of sucrose and concomitant acid production (15). In addition, S mutans have developed a high affinity transport system for sugar uptake during carbohydrate limiting conditions. The phosphoenolpyruvate phosphotransferase system (PEP-PTS) could provide relevant selective advantages (22).

The ability of S. mutans and other facultative anaerobes to persist in the oral environment is at least partly due to their ability to extract energy for biosynthesis from a wide variety of carbohydrates present in the diet of the host...the PEP-PTS offers several important physiological advantages to such microorganisms, which live in ecological niches where environmental conditions are such that the energy source for biosynthesis and growth is widely varied and fluctuates rapidly. These advantages are as folloes: (i) By tightly coupling sugar transport with its subsequent metabolism, the rates of both processes become interdependent, enabling fine control and rapid adaptation to changing environmental conditions. (ii) If conditions change so that the energy source becomes limited (as in the oral cavity during fasting), the energy generating system allows for conservation of ATP because the intracellular transport product is a sugar phosphate that can enter metabolic pathways without further expenditure of energy. (iii) For microorganisms that synthesize and store IPS, PEP-PTS participates in three metabolic systems: transport, glycolysis, and IPS synthesis. By linking catabolism of sugar with biosynthesis of IPS, PEP-PTS acts as an interlocking metabolic key that enables the cell to tune its overall physiology to a changing environment (23).

The continued exposure of the oral cavity to sucrose fluxes would select microorganisms (mutans streptococci and lactobacilli) that have evolved enzyme systems that permit them to function and, therefore, to compete efficiently under these unbalanced growth conditions, and dental caries would be the adventitious result. Americans on average consume approximately $1 \mathrm{~kg}$ of sugar weekly (24). This dietary pressure may affect selective changes in environmental conditions that, in turn, alter the symbiotic nature of the plaque microflora from a state of mutualism to one of parasitism under these rather special conditions of unbalanced growth. Cariogenicity is a manifestation of an amphibiotic shift (20).

\section{PULPAL INFECTION}

The dental pulp, a vascularized connective tissue lined with odontoblasts, is housed within the tooth and is quite vulnerable to bacterial insult. Pulp tissue that is exposed to oral bacteria, through either trauma or deep dental caries, invariably becomes infected and abscessed. Pulpal infections are usually endogenous infections that are caused by a mixture of obligate anaerobes that rely on serum and pulp tissue as their primary source of nutrients. As a result, these microorganisms tend to be proteolytic and they ferment peptides and amino acids for their energy requirements. A low redox potential (Eh), or the ratio of oxidized components to reduced components in a system, results from continued anaerobic metabolism of degraded proteins within a closed pulp chamber. The infected root canal's low Eh environment selects for a restricted group of anaerobic microorganisms that are capable of progressive protein degradation and extensive amino acid fermentation. These microorganisms consist primarily of Bacteroides species, Porphyromonas endodontalis, Eubacterium species, Fusobacterium nucleatum and Peptostreptococcus micros. The exposure of the dental pulp to the indigenous oral microflora results in a parasitic symbiosis that causes pulpal necrosis and an alveolar abscess formation that may potentially endanger the host $(25,26)$.

\section{PERIODONTAL DISEASES}

Inflammatory diseases of the periodontium are caused by the indigenous microflora that live in the gingival sulcus or periodontal pocket between the tooth and the nonkeratinized gingival sulcular epithelium. During active disease, microbial populations approach $10^{11}$ organisms/gram wet weight of plaque biofilm, with more than 500 species present. Germ-free animals do not have inflammatory periodontal disease, and the use of antibiotics is therapeutic for the clinical management of periodontal infections. Both of these facts indicate that bacteria are the primary etiological agents of periodontal disease (27). The complexity of hostsymbiont relationships in periodontal diseases is daunting. The oral host defenses are essential for well-being; however, they may also contribute to pathogenesis. The host response is in a delicate balance of co-recognition with its microbial neighbors that live on the other side of the sulcular epithelium. Immune surveillance and the inflammatory response are fundamental host components involved in the regulation of periodontal disease progression, and refer to comprehensive reviews on the subject $(28,29)$.

The microflora found in the healthy gingival sulcus are usually Gram-positive, facultative anaerobes composed primarily of Streptococcus anginosus and Actinomyces naeslundii (30). If dental plaque is permitted to accumulate with the curtailment of oral hygiene, Gram-negative species, along with motile forms, increase proportionally with the severity of gingival inflammation (31). The onset of gingivitis results in greater species diversity and the emergence of obligate anaerobes, including spirochetes, Fusobacterium nucleatum and Bacteroides species $(32,33)$. The progression to 
advanced periodontitis, with the formation of deep periodontal pockets and a loss of alveolar bone, is associated with Porphyromonas gingivalis, Bacteroides forsythus and Treponema denticola (the so-called 'red complex') (34). As gingival inflammation intensifies, there is an increase in gingival crevicular fluid (GCF) flow (35) and a lowering of Eh, both of which indicate a transition to a highly anaerobic environment. The mean Eh for a healthy gingival sulcus is $+73 \mathrm{mV}$, whereas the mean Eh for a periodontal pocket is $-48 \mathrm{mV}$ (36). Compared with supragingival plaque that is exposed to dietary carbohydrates, subgingival plaque is primarily an asaccharolytic, proteolytic microflora (37). Bleeding that is associated with gingival inflammation releases red blood cells into the sulcular environment, where they may be lysed by bacterial hemolysins (38). The availability of iron in the form of heme (39) and GCF, a rich source of serum protein, is highly selective for proteolytic microorganisms (40). Laboratory studies by ter Steeg and van der Hoeven (41) looked at the changes in subgingival bacteria when they were enriched on human serum. The prolonged growth of subgingival consortiums in a chemostat led to the enrichment of proteolytic microorganisms that were characterized by their progressive protein degradation and extensive amino acid fermentation. The proportional increase of Peptostreptococcus micros, Fusobacterium nucleatum, Eubacterium brachy and T denticola reflected the changes that occur in the subgingival microflora during the natural history of gingivitis (41).

The subgingival microflora are a highly interactive microbial community that is capable of synergistic catabolism within this food web of endogenous nutrients. Sequential reduction in redox potential occurs by the autogenic succession of microbes (42). For example, aerotolerant facultative anaerobes initially reduce available oxygen, a highly reactive electron acceptor. As the syntrophic metabolic activity of these anaerobic consortiums continues, heterotrophic compounds are reduced to acetate, butyrate, ethanol, formate, lactate, propionate and succinate, each creating a niche for continued anaerobic respiration (43). The reduction of these fermentative end products leads to methane production by methanogenic bacteria at the bottom of the energy sink. Methanogenic archaebacteria have been isolated from dental plaque (44). Concomitantly, there is a drop in Eh as the ratio of reduced products to oxidized products increases, making Eh a primary selective pressure in the subgingival microenvironment (45).

Physiological cleansing of the gingival sulcus by GCF is essential for maintaining periodontal health. Stagnation of GCF and the retention of anaerobic microbial communities appear to be significant determinants in the pathogenesis of periodontal diseases. The accumulation of dental plaque biofilm as the result of soft diets, poor oral hygiene, orthodontic bands, restorations with overhanging margins, calculus or foreign objects lodged in the gingival sulcus may lead to an enhanced inflammatory response due to allogenic change $(5,46)$. The selection and propagation of proteolyt- ic anaerobes are key events in the cascading reduction of heterotropic compounds that leads to anaerobiosis, and is driven by microbial syntrophy. The lowering of Eh causes an amphibiotic shift from a mutualistic symbiosis to a parasitic symbiosis. In addition, enhanced virulence expression occurs within the subgingival microflora as Eh levels fall $(47,48)$. P gingivalis demonstrated increased hemagglutination and Arg-gingipain activity at a low redox potential (49). Modulation of virulence could be affected directly by Eh levels. The therapeutic use of methylene blue, which potentially elevates the redox potential in the subgingival environment, has been used in the management of periodontal disease. Shifts in microbial composition from Gram-negative, motile anaerobes to Gram-positive, nonmotile facultative anaerobes, along with improvement in periodontal health, suggest that Eh is an important environmental determinant for the selection of a mutualistic microflora $(50,51)$. Furthermore, cigarette smoking lowers the Eh in the subgingival environment and could, therefore, select for a parasititc microflora (52). Cigarette smoking is a significant predisposing environmental factor in the pathogenesis of periodontal disease (53).

The selection of a parasitic microflora is essential for disease initiation; however, the host response is central to pathogenesis. Impairment of immune function or aberration of the inflammatory response could exacerbate preexisting periodontal infections or result in unique syndromes. Periodontitis is an endogenous infection with a polymicrobial etiology; the host response could account for the varied manifestations of this pandemic disease (54).

\section{CANDIDIASIS}

Colonization of oral tissues and prostheses by yeasts

The oral cavity presents a number of surfaces for Candida species adhesion. These surfaces include epithelial cells, inert polymers of dentures, orthodontic appliances, teeth and oral bacteria. Yeasts are normal inhabitants of the oral ecosystem. Although Candida albicans has been identified as the major representative of the yeast community, other species of yeast or fungi may be present, including Candida dubliniensis, Candida glabrata, Candida tropicalis, Candida krusei, Candida parapsilosis, Trichosporon capitum and Cryptococcus neoformans. The presence of yeasts, per se, is not an indication of infection or disease. C albicans is detected in $20 \%$ of healthy individuals. The carriage rate may reach more than $40 \%$ in hospitalized individuals, which points at an exogeneous, nosocomial acquisition of the yeasts. The carriage rate of Candida species rises under certain conditions, including broad spectrum antibiotic therapy, xerostomia, immunosuppressive therapy, use of steroids in inhalers, diseases such as AIDS and the introduction of dentures or certain orthodontic appliances into the oral ecosystem. Colonization of the oral cavity by Candida species was defined by Cannon (55) as the acquisition and maintenance of a stable population of yeast cells which does not give rise to clinical disease. If the rate of removal is greater than that of acquisition and growth, 
clearance will take place. If the rate is lower and there is tissue damage, it will lead to candidiasis (55).

\section{Denture-related stomatitis and the significance of oral biofilms}

Denture-related stomatitis is a common condition among people who wear complete dentures. It typically develops on the upper maxilla of people who wear dentures (30\% to $75 \%)$ and in young patients who wear palatal expansion appliances, orthodontic appliances and partial or complete dentures. It can result in minor (Newton Type I) to severe (Newton Type II) inflammation and may cause irreversible hyperplasia (Newton Type III). Although it is generally not painful, stomatitis can cause enough discomfort to force patients to remove their dentures. This can affect eating habits and morbidity as well as the success or failure of orthodontic treatments. The etiology of denture stomatitis is complex and multifactorial; however, it shows a strong association with the opportunistic yeast, $\mathrm{C}$ albicans.

Denture plaque formation is thought to be a trigger of the inflammatory process and can offer a suitable field for colonization by opportunistic yeasts. In plaque, microorganisms organize into complex structures that reach equilibrium for a given environment, or maximize their growth and resistance potential, by taking advantage of other microorganisms and the surrounding environment. These structures, called biofilms, are functionally organized assemblies of microorganisms that are encased in an extracellular matrix composed mainly of polysaccharides. This microbial community adheres strongly to the denture, where it thrives on nutrients provided by the oral ecosystem. The intrinsic properties of denture plaque make it an important microbial reservoir, which can lead to persistent and recurrent infections in those who wear dentures. It has been shown that C albicans can form a biofilm in pure culture. Microorganisms that grow in biofilms are better able to resist assaults from the surrounding environment. Denture biofilms are difficult to remove or control, and it is thought that unidentified factors may allow the transformation of 'healthy' plaque toward a pathogenic microbial community which may be responsible for at least three health-related problems: induction of inflammatory lesions and stomatitis or mucosal infections; oral colonization by endogenous and exogenous opportunistic pathogens, and cross contamination; and systemic diseases and remote infections.

The difficulty that pathogenic or opportunistic species, including yeasts, experience in colonizing oral ecosystems may, on the one hand, be related to: interbacterial competition for available space and nutrients; the absence of ligands (adhesins) that allow atypical pathogens to adhere to surfaces; the production of bacteriocins by oral bacteria; the production of surfactants by certain bacteria; and host defense mechanisms. On the other hand, proteolytic bacteria in dental or denture plaque may promote colonization by atypical pathogens by degrading fibronectin on oral surfaces $(56,57)$. In addition, synthetic materials (eg, acrylic) implanted in the mouth may offer suitable surfaces for colonization by some pathogens $(58,59)$.

The very high prevalence of $\mathrm{C}$ albicans in people who wear dentures ( $85 \%$ ), while only $20 \%$ of people who do not wear dentures are infected with $\mathrm{C}$ albicans, is evidence for the selective pressure of dentures within the oral cavity (60). The literature shows that $\mathrm{C}$ albicans colonizes dentures much more frequently than it colonizes the mucosa that is in contact with the denture. Although the proportion of $\mathrm{C}$ albicans in denture plaque increases up to 100 -fold in stomatitis patients, the yeast population represents less than $1 \%$ of the cultivable microbial population that has been isolated from dentures. Preliminary studies of young people who wear partial or complete dentures, palatal expansion appliances or orthodontic appliances (Hawley type) indicate that $\mathrm{C}$ albicans is just as prevalent in this population. Although $\mathrm{C}$ albicans is associated mainly with stomatitis, it is a major opportunistic pathogen that is increasingly involved in serious nosocomial infections (septicemia and pneumonia).

\section{Oral biofilms under the influence of selection forces}

As mentioned previously, the presence of $\mathrm{C}$ albicans is associated strongly with denture stomatitis; however, the exact role of the yeast in the inflammatory process is unknown. $\mathrm{C}$ albicans does not penetrate the mucosa, thus it may exert its effect by releasing virulence factors such as the aspartyl proteases (SAPs) (61). It has been proposed that C albicans does not act alone and that other oral micro-organisms may contribute to the disease induction and progression. In this regard, denture plaque may be implicated because it is known that $\mathrm{C}$ albicans will colonize acrylic more easily if oral streptococci ( $S$ mutans, Streptococcus gordonii, S sanguinis and Streptococcus salivarius) are already present (62). C albicans' SAPs may be induced in a low $\mathrm{pH}$ environment. If denture plaque reacts similarly to dental plaque, it is likely that sugar will cause the production of acid. Mannoproteins that are present on the surface of $\mathrm{C}$ albicans may possess immunomodulatory properties (63), and these molecules, along with other biofilm exopolymers, may induce inflammation.

Oral biofilm formation is controlled by different factors that exert both negative and positive selection pressure on the microbial flora. An imbalance in one or many of these factors may have a major influence on the composition of microbial communities and may result in the transition from a 'healthy' plaque to a pathogenic plaque. One of these factors is beta-defensin. Beta-defensin is an antimicrobial peptide that is produced by epithelial cells of a variety of tissues, including oral mucosa (64) and has a wide spectrum, acting on Gram-positive and Gram-negative bacteria. Human beta-defensin-1 is constitutive, and it serves as a local defense system, possibly to control the local microbial flora. Beta-defensin-2 is also produced by epithelial cells, but its production is induced during inflammation (65). The production is very localized. Beta- 
defensins may act locally, similar to antibiotics. It is thus possible that the presence of beta-defensin ( $h-B D 2)$ perturbates the flora in a localized manner and favours the establishment of $\mathrm{C}$ albicans. The possibilty that inflammation may precede the colonization by $\mathrm{C}$ albicans has been proposed by Budtz- Jorgenson and Bertram (66).

\section{CONCLUSIONS}

We acquire an autochthonous, indigenous microflora that are with us for life - a microflora that are uniquely ours, difficult to change or replace with probiotics, and of vast complexity, with numbers reaching $10^{14} /$ individual body surface (67). Beginning immediately after birth and continuing, the microflora from our mothers or other intimate contacts are transmitted to the surfaces of our bodies (68). Over time, they evolve into mature complex ecosystems that form stable, yet protean, host-symbiont relationships with the host (69). These climax microbial communities become physiologically and genetically diverse as they adapt to the constantly changing environments of our body surfaces $(70,71)$. Moreover, they are homeostatic systems that exist in a state of physiological equilibrium in both health and disease.

The established microbial consortiums of the oral cavity colonize or infect a variety of microhabitats. Collectively,

\section{REFERENCES}

1. Leadbetter ER. Prokaryotic diversity: form, ecophysiology, and habitat. In: Hurst CJ, Knudsen GR, McInerney MJ, Stetzenbach LD, Walter MV, eds. Manual of Environmental Microbiology.

Washington, DC: ASM Press, 1997:14-24.

2. Paster BC, Boches SK, Galvin JL, et al. Bacterial diversity in human subgingival plaque. J Bacteriol 2001;183:3770-83.

3. Caufield PW. Dental caries - a transmissible and infectious disease revisited: a position paper. Pediatr Dent 1997;19:491-8.

4. Socransky SS, Manganiello SD. The oral microbiota from birth to senility. J Periodont 1971;42:485-94.

5. Marsh P, Martin M. Oral Microbiology. 4th edn. Oxford: Wright, 1999.

6. Loesche W. Ecology of the oral flora. In: Newman MG, Nisengard R, eds. Oral Microbiology and Immunology, 2nd edn. Philadelphia: WB Saunders Co, 1994:307-14.

7. Rosebury T. Microorganisms Indigenous to Man. New York: McGraw Hill Book Co, 1962.

8. Marsh PD. Microbial ecology of dental plaque and its significance in health and disease. Adv Dent Res 1994;8:263-71.

9. Sapp J. Evolution by Association. New York: Oxford University Press, 1994

10. Dorland I, Newman WA. Dorland's Illustrated Medical Dictionary, 29th edn. Philadelphia: W.B. Saunders Co, 2000.

11. Stanier RY, Ingraham JL, Wheelis ML, Painter PR. The Microbial World, 5th edn. Englewood Cliffs: Prentice-Hall Co, 1986.

12. Scherp H. Dental caries: prospects for prevention. Science 1971;73:1199-203.

13. Kolenbrander P. Oral microbial communities: biofilms, interactions, and genetic systems. Annu Rev Microbiol 2000;54:413-37.

14. Loesche W. Role of Streptococcus mutans in human dental decay. Microbiol Rev 1986;50:353-80.

15. Liljemark WF, Bloomquist C. Human oral microbial ecology and dental caries and periodontal diseases. Crit Rev Oral Biol Med 1996;7:180-98.

16. van Houte J. Role of micro-organisms in caries etiology. J Dent Res 1994;73:672-81.

17. Brailsford SR, Shah B, Simons D, et al. The predominant aciduric microflora of root-caries lesions. J Dent Res 2001;80:1828-33.

18. De Stoppelaar JD, Van Houte J, Backer Dirks O. The effect of carbohydrate restriction on the presence of Streptococcus mutans, Streptococcus sanguis and iodophilic polysaccharide-producing they contain a composite of all the necessary microorganisms for either localized health or endogenous disease (72). They are continuously bathed in saliva and subjected to the oral functions of mastication and swallowing. The flow and mixing of saliva facilitates microbial dispersion throughout the oral cavity. Microbial availability enriches the selection process and promotes diversity among the myriad of ecohabitats within the oral cavity. The indigenous microflora are capable of engendering health or causing endogenous disease, as determined by the microbial populations selected for by the oral milieu (73).

Oral health or disease is an adventitious event that results from microbial adaptation to the prevailing conditions of the moment. The clinician's intervention for the prevention of endogenous disease can occur only when we realize that ecology is the heart of these host-symbiont relationships. Understanding the processes of change that result in early childhood caries, chronic periodontal diseases, candidiasis or pulpal infections will enable the development of holistic strategies for their prevention. We need to know how to select for the appropriate oral microbes that result in health rather than disease. This will occur only when we look at amphibiosis from an ecological perspective.

bacteria in human dental plaque. Caries Res 1970;4:114-23.

19. van Palenstein Helderman WH, Matee MIN, van der Hoeven JS, Mikx FHM. Cariogenicity depends more on diet than the prevailing mutans streptococcal species. J Dent Res 1996;75:535-45.

20. Ruby JD, Goldner M, Hargreaves JA. Streptococcus mutans: an assessment of its physiological potential in relation to dental caries. Rev Can Biol 1978;37:273-90.

21. Burne RA. Oral streptococci... products of their environment. J Dent Res 1998;77:445-52.

22. Hamilton IR. Ecological basis of dental caries. In: Kuramitsu HK, Ellen RP, eds. Oral Bacterial Ecology. Norfolk: Horizon Scientific Press, 2000:219-274.

23. Calmes RB. Involvement of phosphoenolpyruvate in the catabolism of caries-conducive disaccharides by Streptococcus mutans: lactose transport. Infect Immun 1978;19:934-41.

24. Nordsiek FW. The sweet tooth. Am Scientist 1972;60:41-5.

25. Bartlett JG, Gorbach SL. Anaerobic infections of the head and neck. In: Roth GI, Calmes RB, eds. Oral Biology. St. Louis: CV Mosby Co, 1981:401-28.

26. Sundqvist G. Ecology of the root canal. J Endodont 1992;9:427-30.

27. Socransky SS. Relationship of bacteria to the etiology of periodontal disease. J Dent Res 1970;49:203-18.

28. Darveau R. Oral innate host defense responses: interactions with microbial communities and their role in the development of disease. In: Kuramitsu HK, Ellen RP, eds. Oral Bacterial Ecology. Norfolk: Horizon Scientific Press, 2000:169-218.

29. Genco RJ. Host responses in periodontal diseases: current concepts. J Periodont 1992;63:338-55.

30. Marsh P. Oral ecology and its impact on microbial diversity. In: Kuramitsu HK, Ellen RP, eds. Oral Bacterial Ecology. Norfolk: Horizon Scientific Press, 2000:11-65.

31. Loe $\mathrm{H}$, Theilade $\mathrm{E}$, Jensen $\mathrm{S}$. Experimental gingivitis in man. J Periodont 1965;36:177-87.

32. Moore WEC. Microbiology of periodontal diseases. J Periodont Res 1987;22:335-41.

33. Moore WEC, Moore LVH. The bacteria of periodontal diseases. Periodont 2000 1994;5:66-77.

34. Socransky SS, Haffajee AD, Cugini MA, Smith C, Kent RL Jr. Microbial complexes in subgingival plaque. J Clin Periodont 1998;25:134-44.

35. Lamster IB, Hartley LJ, Vogel RI. Development of a biochemical 
profile for gingival crevicular fluid. J Periodont 1985;56:S13-21.

36. Kenney EB, Ash MM. Oxidation reduction potential of developing plaque, periodontal pockets and gingival sulci. J Periodont 1969;40:630-3.

37. Bloomquist CG, Liljemark WF. Dental plaque. In: Nataro JP, Blaser MJ, Cunningham-Rundles S, eds. Persistent Bacterial Infections. Washington: ASM Press, 2000:409-22.

38. Grenier D. Characteristics of hemolytic and hemagglutinating activities of Treponema denticola. Oral Microbiol Immunol 1991;6:246-9.

39. Mukherjee $S$. The role of crevicular fluid iron in periodontal disease. J Periodont 1985;56:22-7.

40. Genco CA, Dixon DW. Emerging strategies in microbial haem capture. Mol Microbiol 2001;39:1-11.

41. ter Steeg PF, van der Hoeven JS. Development of periodontal microflora on human serum. Microb Ecology Health Dis 1989;2:1-10

42. Grenier D, Mayrand D. Periodontitis as an ecological imbalance. In: Kuramitsu HK, Ellen RP, eds. Oral Bacterial Ecology. Norfolk: Horizon Scientific Press, 2000:275-310.

43. Shah NH, Gharbia SE. Oral and dental disease. The biochemical milieu of the host in the selection of anaerobic species of the oral cavity. Clin Infect Dis 1995;20:S291-300.

44. Belay N, Johnson R, Rajagopal B, Conway de Macario E, Daniels L. Methanogenic bacteria from human dental plaque. Appl Environ Microbiol 1988;54:600-3.

45. Goldner M. The biological aspects of oral pathogenicity. J Hygeine Epidem Microbiol Immunol 1981;25:431-8.

46. Newman HN. Plaque and chronic inflammatory periodontal disease. J Clin Periodont 1990;17:533-41.

47. Marett D, Lacey B, Goldner M. Microbial pathogenesis: an energetic interpretation. Speculations Sci Tech 1994;17:301-7.

48. Goldner M. Virulence modulon theory of pathogenicity. Acta Biotheoretica 1997;45:81-5.

49. Leke N, Grenier D, Goldner M, Mayrand D. Effects of hydrogen peroxide on growth and selective properties of Poryphymonas gingivalis. FEMS Microbiol Lett 1999;174:347-53.

50. Wilson M, Gibson M, Strahan D, Harvey W. A preliminary evaluation of the use of a redox agent in the treatment of chronic periodontitis. J Periodont Res 1992;27:522-7.

51. Ower PC, Ciantar M, Newman HN, Wilson M, Bulman JS. The effects of chronic periodontitis of a subgingivally-placed redox agent in a slow release device. J Clin Periodont 1995;22:494-500.

52. Kenny EB, Saxe SR, Bowles RD. The effect of cigarette smoking on anaerobiosis in the oral cavity. J Periodont 1975;46:82-5.

53. Zambon JJ, Grossi SG, Machtei EE, Ho AW, Dunford R, Genco RJ. Cigarette smoking increases the risk for subgingival infection with periodontal pathogens. J Periodont 67;1996:1050-4.

54. Darveau RP, Tanner A, Page, RC. The microbial challenge in periodontitis. Periodontol 2000 1997;14:12-32.

55. Cannon RD, Chaffin WL. Oral colonization by Candida albicans.
Crit Rev Oral Biol Med 1999;10:359-83.

56. Wilkström M, Linde A. Ability of oral bacteria to degrade fibronectin. Infect Immun 1986;51:707-11.

57. Childs WC, Gibbons RJ. Selective modulation of bacterial attachment to oral epithelial cells by enzyme activities associated with poor oral hygiene. J Periodont 1990;25:172-8.

58. Cunliffe D, Smart CA, Alexander C, Vulfson EN. Bacterial adhesion at synthetic surfaces. Appl Environ Microbiol 1999;65:4995-5002.

59. Edgerton M, Scannapieco FA, Reddy MS, Levine MJ. Human submandibular-sublingual saliva promotes adhesion of Candida albicans to polymethylmethacrylate. Infect Immun 1993;61:2644-52.

60. Cannon RD, Chaffin WL. Oral colonization by Candida albicans. Crit Rev Oral Biol Med 1999;10:359-83.

61. Naglik JR, Newport G, White TC, et al. In vivo analysis of secreted aspartyl proteinase expression in human oral candidiasis. Infec Immun 1999;67:2482-90.

62. Fellermann K, Stange EF. Defensins - innate immunity at the epithelial frontier. Eur J Gastroenterol Hepatol 2001;13:771-6.

63. Pietrella D, Cherniak R, Strappini C, et al. Role of mannoprotein in induction and regulation of immunity to Cryptococcus neoformans. Infect Immun 2001;69:2808-14.

64. Mathews M, Jia HP, Guthmiller JM, et al. Production of betadefensin antimicrobial peptides by the oral mucosa and salivary glands. Infect Immun 1999;67:2740-5.

65. Schonwetter BS, Stolzenberg ED, Zasloff MA. Epithelial antibiotics induced at sites of inflammation. Science 1995;267:1645-8.

66. Budtz-Jorgensen E, Bertram U. Denture stomatitis. I. The etiology in relation to trauma and infection. Acta Odontol Scand 1970;28:61-9.

67. Henderson B, Wilson M. Commensal communism and the oral cavity. J Dent Res 1998;77:1674-83.

68. Bettelheim KA. The natural history and ecology of commensal human flora. In: Nataro JP, Blaser MJ, Cunningham-Rundles S, eds. Persistent Bacterial Infections. Washington: ASM Press, 2000:101-14.

69. Wold AE, Adlerberth I. Pathological consequences of commensalism. In: Nataro JP, Blaser MJ, Cunningham-Rundles S, eds. Persistent Bacterial Infections. Washington: ASM Press, 2000:115-44.

70. Kilian M. Clonal basis of bacterial virulence. In: Guggenheim B, Shapiro S, eds. Oral Biology at the Turn of the Century. Basel: Karger, 1988:131-42.

71. Bowden GHW. Oral biofilm an archive of past events? In: Newman $\mathrm{H}$, Wilson M, eds. Dental Plaque Revisited: Oral Biofilms in Health and Disease. Cardiff: Bioline Publishing, 1999:211-35.

72. Tanner ACR, Milgrom PM, Kent R Jr, et al. The microbiota of young children from tooth and tongue samples. J Dent Res 2002;81:53-7.

73. Marcotte H, Lavoie MC. Oral microbial ecology and the role of salivary immunoglobulin A. Microbiol Mol Biol Rev 1998;62:71-109. 


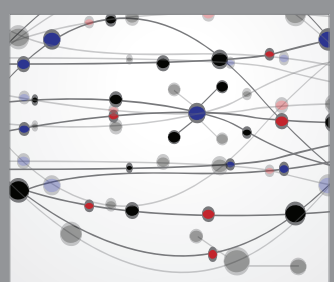

The Scientific World Journal
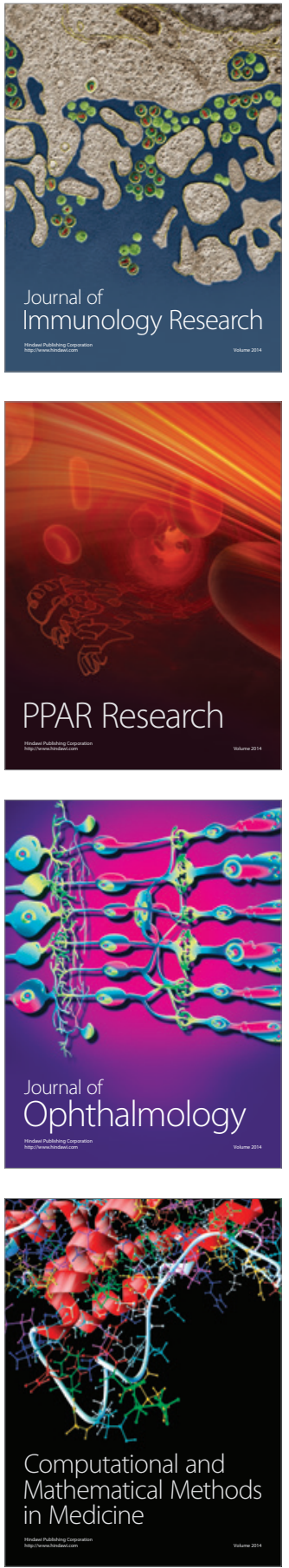

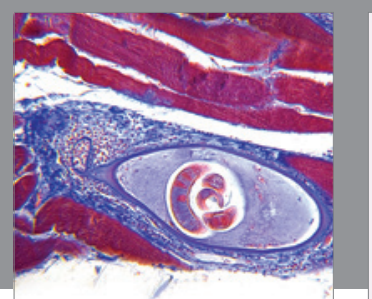

Gastroenterology Research and Practice

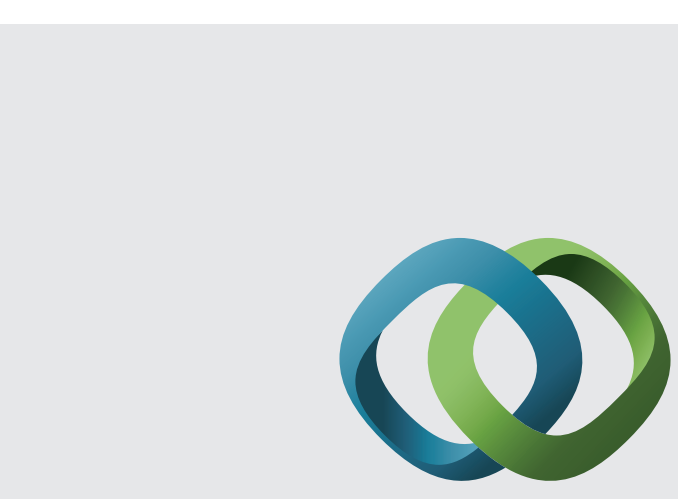

\section{Hindawi}

Submit your manuscripts at

http://www.hindawi.com
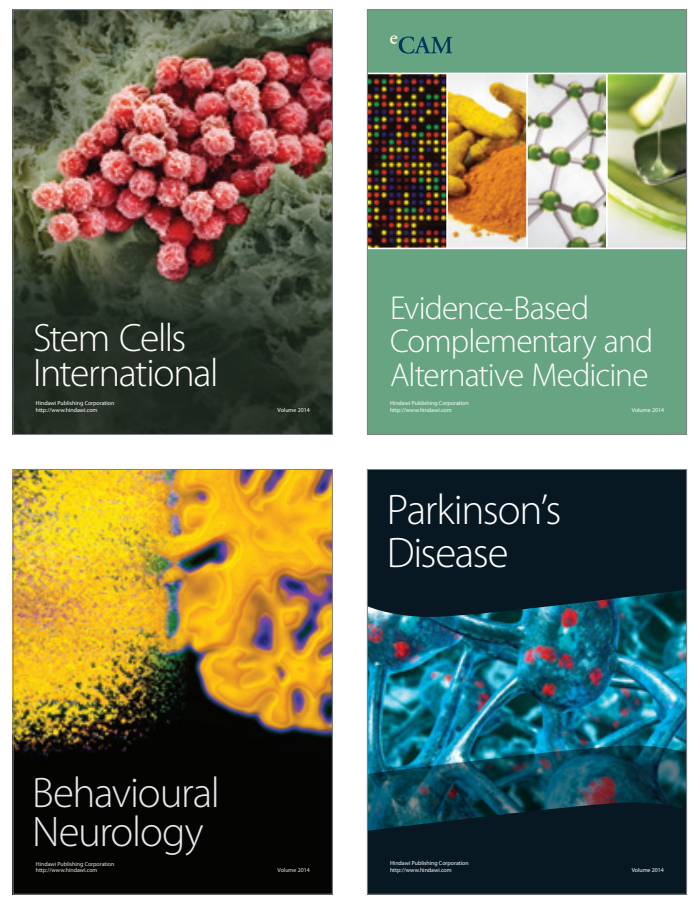
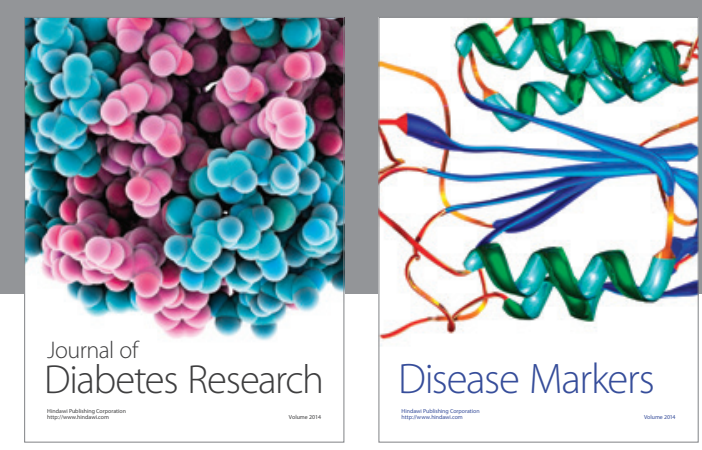

Disease Markers
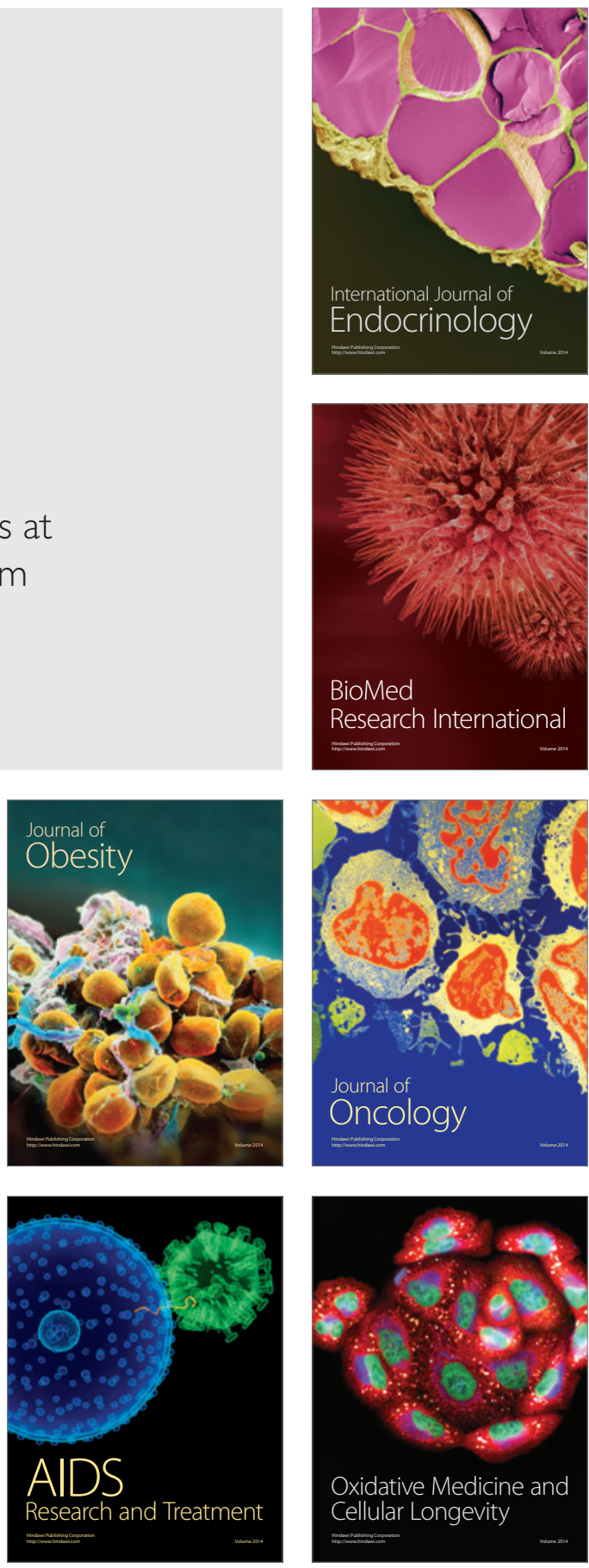